\title{
Marcadores SNP: conceitos básicos, aplicações no manejo e no melhoramento animal e perspectivas para o futuro
}

\begin{abstract}
Alexandre Rodrigues Caetano ${ }^{1}$
${ }^{1}$ Embrapa Recursos Genéticos e Biotecnologia, Brasilia-DF.

RESUMO - Os primeiros estudos de identificação, caracterização e utilização de marcadores moleculares para a caracterização de recursos genéticos e geração de ferramentas para o melhoramento animal datam do final da década de 80 . Nos últimos 20 anos as tecnologias para geração de dados moleculares passaram por vários ciclos de renovação. A última onda de inovações tecnológicas representa uma verdadeira revolução e trouxe metodologias para identificar e genotipar marcadores SNP (do inglês Single Nucleotide Polimorphism) de maneira massal. Chips de DNA de alta densidade foram criados para genotipar de dezenas de milhares até centenas de milhares de marcadores SNP em um único ensaio. Além disso, outras tecnologias de média densidade permitem também a genotipagem de dezenas a centenas de marcadores, em números elevados de amostras, com altíssima velocidade e automação. Essas novas tecnologias permitiram a geração de novas aplicações, como as metodologias para avaliação genética e seleção com base no Valor Genômico (Genomic Estimated Breeding Value-GEBV). Os métodos estatísticos para avaliação e seleção genômica estão em pleno desenvolvimento, mas a tecnologia já se tornou uma realidade com o lançamento do primeiro sumário de touros para a raça Holandesa com GEBVs para características de produção e qualidade do leite em janeiro de 2009. Além disso, essas tecnologias também trouxeram novas opções para desenvolvimento de testes diagnósticos para confirmação de paternidade, identificação individual, rastreabilidade, etc. Além dessas inovações, as novas tecnologias de genotipagem de marcadores SNP facilitaram também o desenvolvimento de serviços terceirizados de geração de dados, permitindo que qualquer grupo realize pesquisas avançadas, sempre com as tecnologias mais avançadas, sem a necessidade de investimentos em equipamentos.
\end{abstract}

Palavras-chave: marcadores moleculares, Polimorfismo de Base Única, seleção genômica

\section{SNP markers: basic concepts, applications in animal breeding and management and perspectives for the future}

\begin{abstract}
The first studies to identify, characterize and use molecular markers to characterize genetic resources and generate tools for animal breeding and management date from the end of the $80 \mathrm{~s}$. In the last 20 years the technologies to generate molecular data went through several innovation cycles. The last wave of technological innovations represents a true revolution, bringing methods to identify and genotype SNP (Single Nucleotide Polymorphism) markers in large scale. High density DNA chips were generated to genotype from tens of thousands to hundreds of thousands of SNPs in a single assay. Furthermore, other medium density technologies allow for the genotyping of tens to hundreds of makers, in high numbers of samples, with very high speed and automation. These new technologies allowed for the generation of new applications, such as the methods to genetically evaluate and select animals based on their Genomic Value (Genomic Estimated Breeding Value-GEBV). The statistical methods for genomic evaluation and selection are in full development, but the technology already became reality with the release of the first bull summary for the Holstein breed with GEBVs for milk production and quality traits in January 2009. In addition, these technologies brought new options for development of diagnostic tests for paternity testing, individual identification, traceability, etc. Also, these new technologies to genotype SNP markers facilitated the development of outsourcing companies to generate molecular data, allowing any group to conduct advanced experiments, always using the most advanced technologies, without the need of investments into equipment.
\end{abstract}

Key Words: molecular markers, genomic selection, Single Nucleotide Polymorphism

\section{Introdução}

Os primeiros trabalhos para desenvolver e caracterizar marcadores moleculares para espécies de interesse zootécnico datam do início dos anos 80. As primeiras publicações relatam resultados de estudos de caracterização de marcadores RFLP (do inglêsRestriction Fragment Length Polymorphism) em suínos (Chardon et al., 1985) e bovinos (Beckmann et al., 1986, Georges et al., 1987). Foram estudos iniciais, com metodologias 
trabalhosas e com muitos limites, mas que na época eram consideradas inovadoras, uma vez que as alternativas disponíveis resumiam-se a estudos com grupos sanguíneos e aloenzimas. Tipicamente, para produzir um dado molecular (um genótipo) eram necessários em média cinco dias de trabalho, utilizando radioisótopos e enfrentando várias questões técnicas que dificultavam o trabalh o.

Nos anos seguintes, foram realizados os primeiros estudos para isolar e caracterizar marcadores do tipo SSR (Simple Sequence Repeats). Esforços significativos foram empregados para identificar microsatélites em bovinos (Fries et al., 1990; Moore et al., 1994; Vaiman et al., 1994; Stone et al., 1995; Kirkpatrick et al., 1995; Stone et al., 1997; Reed et al., 2001), suínos (Johansson et al., 1992; Miller et al., 1992; Coppieters et al., 1993; Fredholm et al., 1993; Alexander et al., 1996) e eqüinos (Johansson et al., 1992; Marklund et al., 1994; Hopman et al., 1999; Murphie et al. 1999; Ruth et al., 1999). Tal metodologia trouxe muitos benefícios, associados, principalmente, às bases moleculares desse tipo de marcador (Tabela 1). Inicialmente a genotipagem destes marcadores era realizada com o uso de radioisótopos. Posteriormente, com a invenção dos equipamentos dos seqüenciadores automáticos, tornou-se possível utilizar fluorocromos para detecção dos variantes alélicos. Os primeiros mapas genéticos abrangentes para espécies de interesse zootécnico foram construídos com marcadores microssatélites (Barendse et al., 1994; Rohrer et al., 1994; Guerin et al., 2003).

Avanços tecnológicos recentes trouxeram metodologias de alto desempenho e acurácia, e baixo custo e mão-de-obra para prospecção, caracterização e genotipagem de marcadores SNP (Single Nucleotide Polymorphism). Essas tecnologias trouxeram novas soluções para aplicações já solidificadas e também estão permitindo o desenvolvimento de novas aplicações, produtos e processos, com uso direto nas cadeias produtivas da pecuária mundial. O objetivo desse texto é esclarecer esses recentes avanços e fornecer perspectivas de como essas tecnologias poderão impactar a pecuária nacional.

\section{Bases moleculares dos marcadores SNP}

Os marcadores SNP tem como base as alterações mais elementares da molécula de DNA, ou seja, mutações em bases únicas da cadeia de bases nitrogenadas (Adenina, Citosina, Timina e Guanina). As mutações mais comuns são as transições, onde ocorrem trocas de uma purina por outra purina (A "! G) ou de uma pirimidina por outra pirimidina (C "! T). Menos freqüentes, as transversões ocorrem quando há troca de uma purina por uma pirimidina, ou vice-versa(C/ T”! A/G). Normalmente, os marcadores SNP são bi-alélicos, ou seja, geralmente são encontrados apenas dois variantes em uma espécie (Ex: um alelo corresponde a um par de bases A/T e o outro a um G/C). Os SNPs podem ocorrer em regiões codificadoras ou com função regulatória, porém, na maior parte das vezes são encontrados em espaços intergênicos, sem função determinada.

Os SNPs são extremamente abundantes nos genomas de espécies não endogâmicas. Estudos com humanos, e com espécies de interesse zootécnico, mostram que pode haver milhões de polimorfismos SNP no genoma de um indivíduo (Bovine Genome Sequencing and Analysis Consortium, 2009; Li et al., 2009). Além dos marcadores SNP serem abundantes, suas bases moleculares permitem que haja uma distribuição homogênea de SNPs pelo genoma.

A existência de SNPs no genoma não é novidade. Os primeiros trabalhos de seqüenciamento de fragmentos específicos de DNA detectaram esse tipo de polimorfismo (Orita et al., 1989). Além disso, os SNPs são a base molecular de vários tipos de marcadores moleculares que foram desenvolvidos com diferentes metodologias ao

Tabela 1 - Comparações entre os marcadores moleculares RFLP, Microssatélite e SNP

\begin{tabular}{lccc}
\hline & RFLP & Microsatélite & SNP \\
\hline Quantidade de DNA Necessária & $10 u g$ & $50 \mathrm{ng}$ & $50 \mathrm{ng}$ \\
Qualidade do DNA Necessária & Ótima & Razoável & Boa \\
Baseado em PCR & Não & Sim & Sim \\
Radioatividade & Sim & Sim/Não & Não \\
Multiplex & Não & Sim & SIM \\
Facilidade de Uso & Não & Sim & Sim \\
Automação & Não & Boa & Boa \\
Reprodutibilidade & Boa & Alto & Baixo \\
Custo de Desenvolvimento & Baixo & Multi-alélico & Bi-alélico \\
Número de Alelos por Loco & Ótima & Boa \\
Informatividade por Loco & Bi-alélico & 1.000 s & Milhões \\
Abundância/Distribuição pelo genoma & Boa & Baixo & BAIXÍSSIMO \\
Custo por dado gerado & $100 \mathrm{~s}$ & &
\end{tabular}


longo das últimas três décadas, como RFLPs, RAPDs, AFLPs, entre outros.

A utilização de marcadores moleculares SNP em estudos de associação e mapeamento genético, assim como em ensaios diagnósticos para confirmação de paternidade, identificação individual (rastreabilidade), detecção de doenças genéticas e/ou polimorfismos associados a características de produção, esteve limitada por muito tempo devido à restrições tecnológicas. Esse quadro mudou radicalmente nos últimos anos com a geração de novas tecnologias para descoberta e genotipagem em massa de SNPs.

Evolução nos métodos de prospecção de marcadores SNP

Até recentemente o método padrão de prospecção de marcadores SNP era baseado no método de seqüenciamento Sanger. A detecção de SNPs distribuídos aleatoriamente pelo genoma se dá através do alinhamento de uma seqüência de um fragmento aleatório do genoma com uma seqüência consenso (Figura 1). Esse processo é limitado pela capacidade de geração e análise de seqüências de um laboratório, assim como pela necessidade da existência de uma seqüência referência - o genoma da espécie tem de estar seqüenciado. Programas de bioinformática com o PHRED, PHRAP, e o CONSED (Ewin et al, 1998; Gordon et al. 1998) foram desenvolvidos para automatizar o máximo possível a fase de análise de dados, permitindo grandes avanços. Grandes conjuntos de SNPs foram detectados em todas as espécies que tiveram seus genomas seqüenciados utilizando esta metodologia. (Referencia para humanos, bovino, etc).

Alternativas para prospectar SNPs em regiões específicas do genoma, utilizando seqüenciamento Sanger também foram desenvolvidas e extensamente aplicadas. $\mathrm{O}$ seqüenciamento direto de fragmentos específicos do genoma amplificados por PCR, e subseqüente alinhamento e

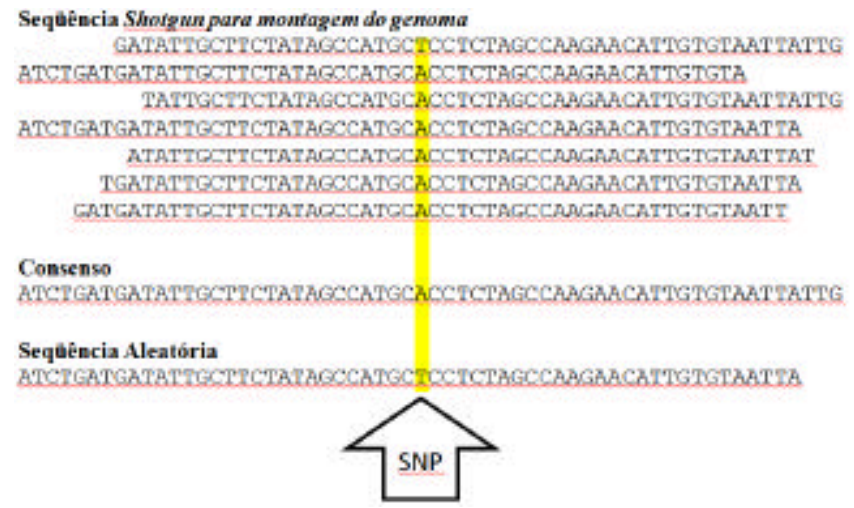

Figura 1 - Prospecção de SNPs em seqüências aleatórias.x comparação das seqüências (Figura 2), permite a mineração de SNPs em uma região de interesse. Vários estudos utilizaram essa metodologia para prospectar SNPs em genes de interesse (Lai et al., 1998; Fahrenkrug et al., 2002; Calvo et al., 2006; Abatepaulo et al., 2008).

As duas metodologias citadas são sólidas e eficazes, porém, os custos envolvidos e a mão-de-obra necessária são relativamente altos. A prospecção de SNPs aleatórios apresenta um custo estimado de US\$3 por SNP detectado. Já a detecção de SNPs em fragmentos específicos do genoma tem um custo da ordem de US\$10 por SNP.

O desenvolvimento de novas metodologias de seqüenciamento mudou radicalmente o cenário descrito, baixando custos e acelerando tremendamente a velocidade na qual o trabalho pode ser realizado. As chamadas tecnologias de seqüenciamento de segunda geração (Roche 454 -Margulies et al. 2005, Solexa-Illumina - Bennett 2004 e ABI Solid -Valouev et al., 2008) são capazes de produzir vastos conjuntos de dados (da ordem de milhões de bases seqüenciadas) em um único experimento altamente automatizado, com duração de 48 horas.

Já existem exemplos práticos da aplicação dessas tecnologias para prospecção de SNPs. Um estudo recente com bovinos (Van Tassell et al., 2008) prospectou um total de 62.042 SNPs, a um custo de US\$0.48 por SNP, utilizando o Illumina/Solexa Genome Analyzer. Embora muito mais eficiente que o seqüenciamento tradicional, a estratégia utilizada ainda depende da disponibilidade de

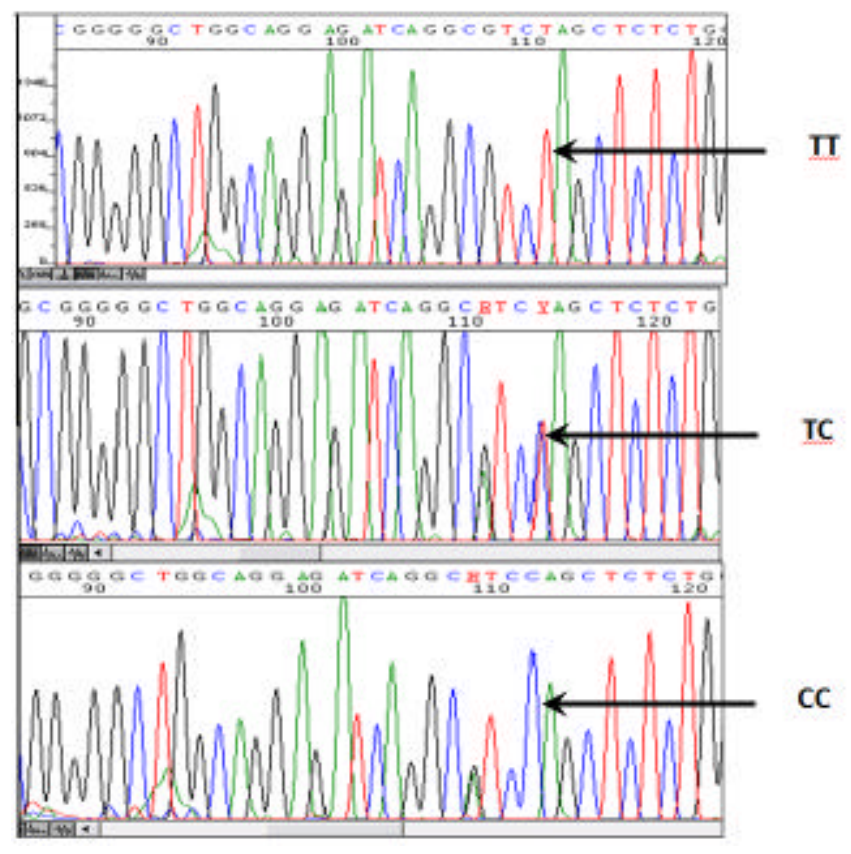

Figura 2 - Prospecção de SNPs em regiões genômicas específicas com o sequênciamento direto de produtos de PCR. 
uma seqüência referência do genoma. Alternativas para prospecção de SNPs em genomas não seqüenciados também já foram encontradas. Novaes et al. (2008) desenvolveram uma metodologia para minerar SNPs em seqüências de eucalipto, cujo genoma ainda não fora seqüenciado, utilizando tecnologia Roche 454. Adicionalmente, outras tecnologias, em breve disponíveis comercialmente, tem potencial para seqüenciar genomas inteiros em horas, a um custo previsto entre US\$500 e \$1000 (Eid et al., 2009), o que certamente trará uma nova onda de inovação e aplicações nesse área.

Evolução nos métodos de genotipagem de marcadores SNP

O método mais básico para genotipagem de SNPs em regiões específicas do genoma é baseado na técnica de PCR-RFLP (Maeda et al. 1989). O fragmento contendo o SNP de interesse é amplificado com iniciadores específicos, purificado e submetido a um tratamento com uma enzima de restrição que reconheça apenas um dos alelos. Posteriormente, os fragmentos são separados por eletroforese para diferenciação dos alelos por tamanho. Além de extremamente trabalhoso, para o emprego desse método, é necessário que haja uma enzima de restrição que diferencie os dois alelos, o que nem sempre é possível. Adicionalmente, essa metodologia não permite a paralelização de ensaios - geralmente, só é possível genotipar um loco por ensaio. Por outro lado, é uma técnica que não requer equipamentos avançados: apenas um termociclador e equipamentos de eletroforese. O PCR aleloespecífico (Allele-Specific PCR) foi outra metodologia gerada para genotipar SNPs sem equipamentos especiais,no entanto também é laboriosa (Saiki et al., 1986).
O próximo avanço tecnológico para genotipagem de SNPs surgiu com metodologias que utilizam seqüenciadores automáticos para a realização da eletroforese de produtos de PCR marcados com corantes fluorescentes. Após a amplificação do fragmento desejado, realiza-se uma mineração do seqüenciamento com a finalidade de se determinar o genótipo na base desejada (Figura 3A). A metodologia permite a genotipagem de mais de um SNP em um mesmo fragmento, ou em fragmentos diferentes. Em termos práticos, é possível genotipar até 10 SNPs em um mesmo ensaio. Embora essa metodologia tenha trazido um grande avanço, e seja baseada em equipamentos que normalmente são encontrados em instituições de ensino/ pesquisa (seqüenciadores automáticos de DNA), ainda é necessário uma grande quantidade de trabalho para geração de dados. Seguindo a mesma tendência, foram geradas metodologias para genotipar SNPs utilizando equipamentos de PCR em Tempo Real (Real Time PCR), que até então haviam sido concebidos para quantificação de RNA mensageiros, para a condução e estudos de expressão gênica (Figura 3B).

Metodologias de genotipagem de SNPs baseadas em microarranjos de DNA fabricados através da impressão de oligonucleotídeos em lâminas de vidro (Hacia et al. 1999) trouxeram novos avanços, com aplicações sendo geradas inclusive para espécies de interesse pecuário (Kamiñski et al., 2005; Chessa et al., 2007; Figura 4A). Essa tecnologia permite a genotipagem de dezenas de marcadores no mesmo ensaio com uma diminuição significativa de mãode-obra. Porém, o sucesso da implementação desse método está na fase de produção dos microarranjos que por sua vez requer grande expertise e não é simples de ser padronizada.

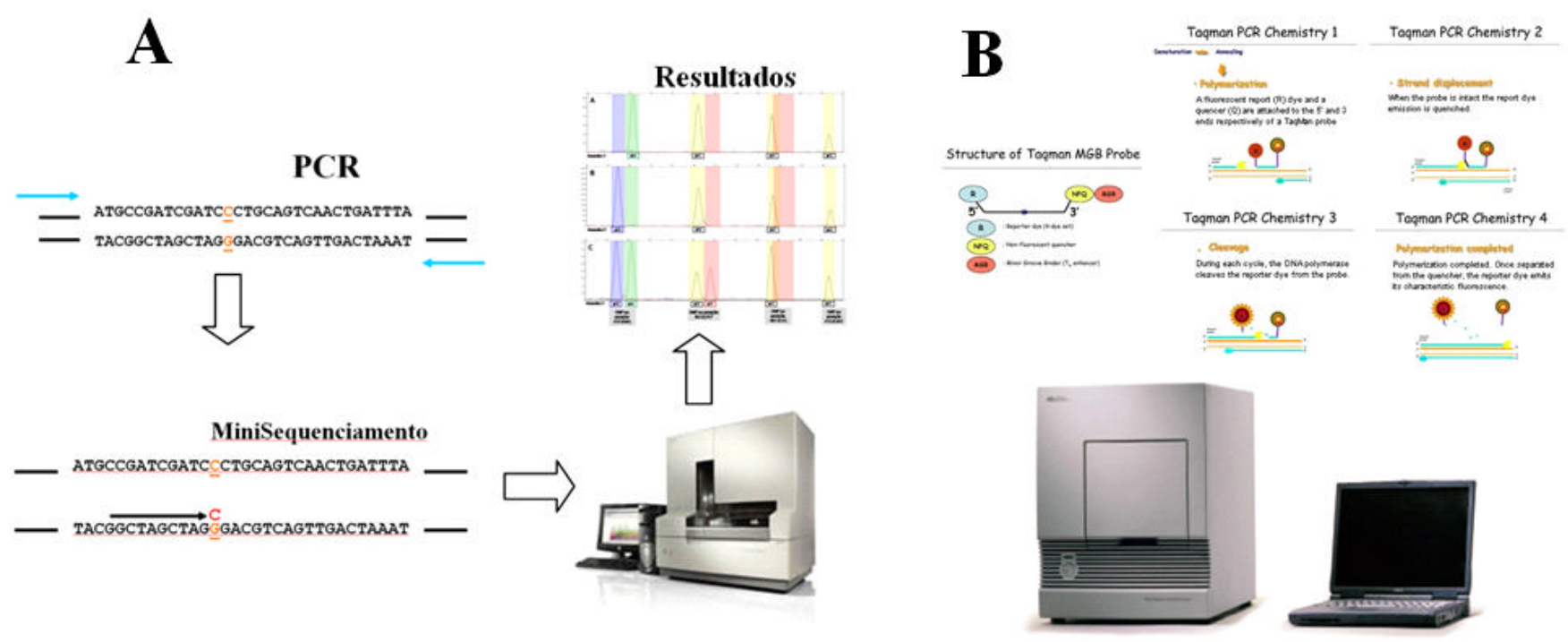

Figura 3 - Genotipagem de SNPs por minisequenciamento (A) e por ensaio Taqman com equipamento de PCR Tempo Real. 
Outra alternativa para genotipagem de dezenas de SNPs em paralelo foi estabelecida com uso de equipamentos de espectometria de massa (MALD-TOF, Figura 4B). Essa tecnologia oferece ensaios extremamente reprodutíveis e de baixo custo, porém o investimento inicial em equipamentos é muito alto (Tang et al., 1999). Mais recentemente, várias novas tecnologias para genotipagem de SNPs nessa escala têm sido apresentadas por diferentes empresas (Illumina - BeadExpress, ABI/BioTrove OpenArrary, ABI-SNPlex, ABI-TaqMan, etc.). Cada uma dessas tecnologias tem vantagens e desvantagens técnicas e custos variados. O ponto em comum entre qualquer uma dessas plataformas é que os ensaios para SNPs específicos podem ser adaptados para todas as tecnologias, permitindo que a mesma informação genotípica possa ser acessada, independentemente da tecnologia utilizada.

O desenvolvimento de metodologias para genotipar de dezenas de milhares até um milhão de SNPs em um único ensaio (Figura 5) trouxe novos benefícios e aplicações, levando os custos de geração de dados de US\$0,10 a US\$0,001 por SNP genotipado (Tabela 1). Chips de genotipagem de alta densidade já foram gerados e validados para humanos, bovinos, ovinos, eqüinos, suínos e caninos (veja Illumina), contendo em média mais de 50 mil SNPs. Em algumas espécies, novos chips, contendo maiores números de SNPs já estão em desenvolvimento, refletindo o uso extenso que a tecnologia alcançou e as necessidades de aplicações específicas de cada setor.

\section{Aplicações e relações com tecnologias anteriores}

As tecnologias de genotipagem de SNP citadas foram aplicadas primeiramente para desenvolvimento de ensaios diagnósticos para doenças genéticas (Holloway et al., 1999). Nesses casos, a demanda da aplicação é testar um número baixo de polimorfismos em um grande número de amostras, com rapidez e alta acurácia. As soluções tecnológicas mais adequadas para essas aplicações são os ensaios Taqman ou de minisequenciamento (Figura 3). Questões como alta repetibilidade e robustez, e facilidade de padronização dos ensaios trouxeram grandes vantagens para a implementação de diferentes testes com diferentes plataformas e em diferentes laboratórios.

Metodologias para testes de exclusão de paternidade e identificação individual também foram desenvolvidas com marcadores SNP (Heaton et al., 2002). Adicionalmente, painéis de baixa densidade foram gerados para rastreabilidade de amostras (Heaton et al., 2005) e também para diagnosticar polimorfismos em genes associados a características de produção (Chessa et al., 2007, Merial Igenity ${ }^{\circledR)}$. Essas aplicações requerem a genotipagem de algumas dezenas de marcadores em grandes números de amostras, demandando quesitos não oferecidos pelos ensaios Taqman e de minisequenciamento. As tecnologias geralmente utilizadas nessas aplicações foram as plataformas baseadas em espectrometria de massa (MALD-TOF, Heaton et al., 2005) e em microarranjos (Kaminski et al., 2005; Chessa et al., 2007).

Uma das grandes vantagens dos marcadores SNP citada é a fácil conversão dos ensaios entre diferentes plataformas.
A
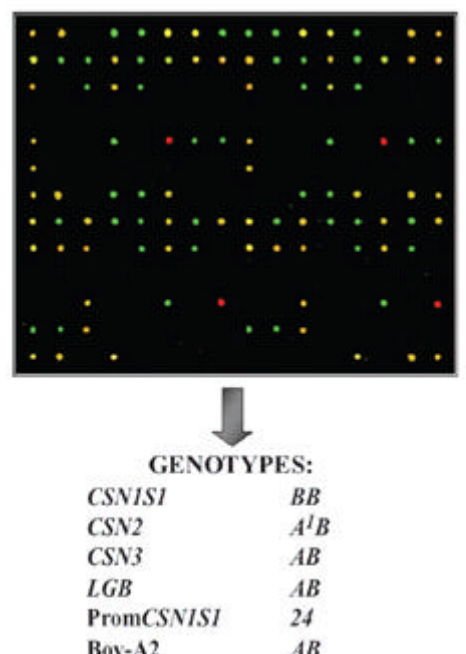
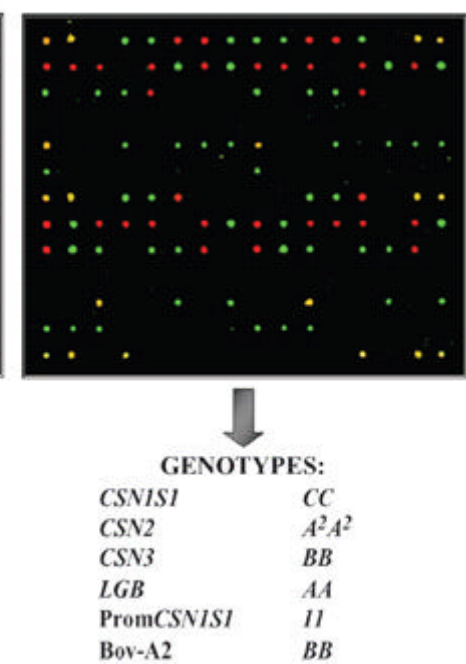

Bov-A2

Fonte: Chessa et al., 2007

\section{B}
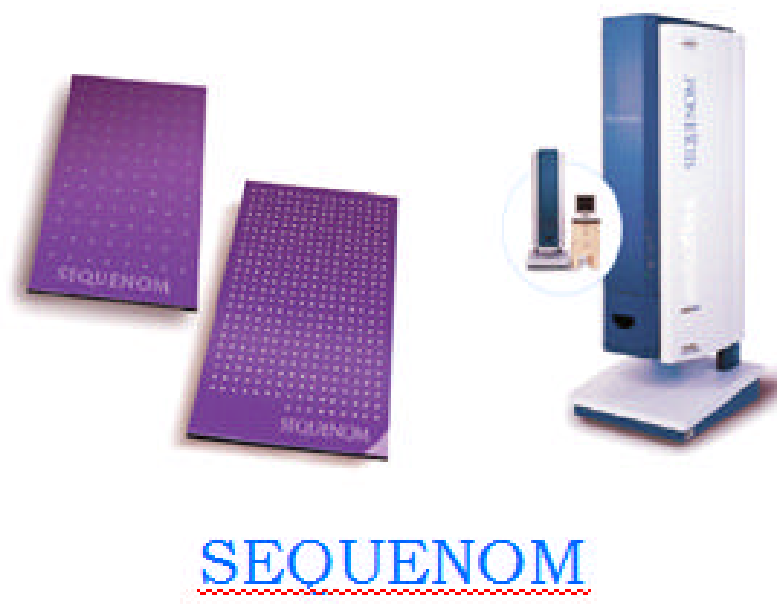

Figura 4 - Exemplo de genotipagem de SNPs com microarrajos (A) e com tecnologia de espectrometria de massa MALD-TOF (B). 
A

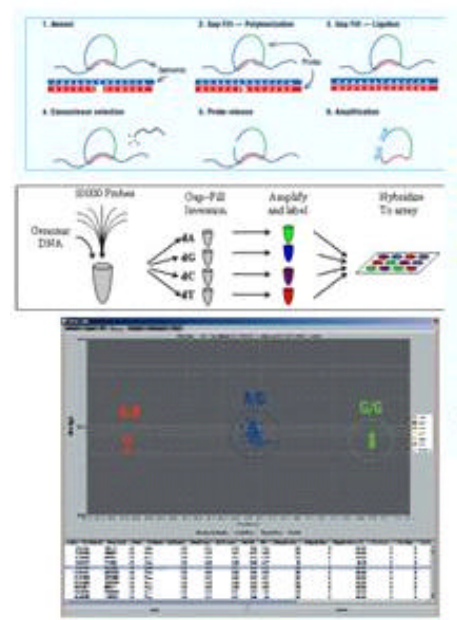

B

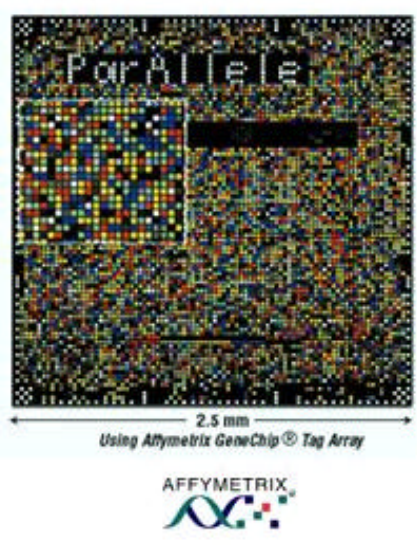

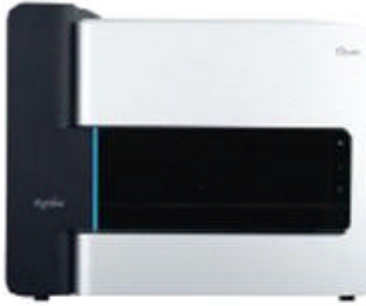

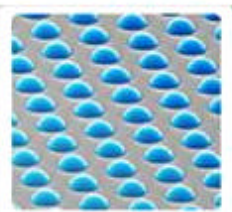

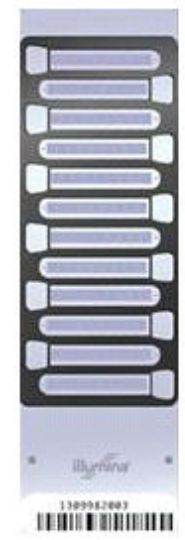

|IIIIก IIIIIIIII

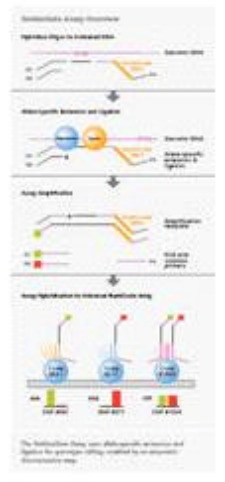

Figura 5 - Ilustração de Tecnologias para Genotipagem de Dezenas de Milhares até Milhões de SNPs em paralelo (A - Affymetrix/ ParAllele, B - Illumina IScan).

Novas plataformas para genotipagem de painéis de SNPs de baixa e média densidade estão disponíveis e sendo geradas (Illumina - BeadExpress, ABI/BioTrove - OpenArrary,). A fácil transferência dos ensaios entre plataformas aumenta a competição ente as empresas geradoras de tecnologia, levando a melhoras das tecnologias e redução de custos.

Os chips de genotipagem de alta densidade, com dezenas de milhares de marcadores SNP (Bovine HapMap Consortium, 2009; Matukumalli et al., 2009) trouxeram grandes avanços para os estudos direcionados para identificação de genes que controlam características de interesse econômico. Até o desenvolvimento dessa tecnologia, um estudo inicial de mapeamento em bovinos era tipicamente executado com um mínimo de 150 marcadores microssatélites, com espaçamento médio mínimo de $20 \mathrm{cM}$ (equivalente a $\sim 18$ milhões de pares de bases), a um custo de US $\$ 10$ por genótipo. Posteriormente, em fases subseqüentes do projeto, marcadores adicionais tinham de ser adicionados ao mapa para refinar regiões de interesse. Como os ensaios com microssatélites não aceitam um alto nível de paralelização (tipicamente, apenas 3 a 5 loci podem ser genotipados na mesma reação), uma mesma amostra tem de ser manuseada dezenas de vezes, aumentando as chances de erros laboratoriais. Comumente, a fase de geração de dados moleculares para um estudo de mapeamento com microssatélites se estende por meses, envolvendo o trabalho de várias pessoas em laboratórios diferentes.

Os chips de genotipagem de SNPs de alta densidade mudaram radicalmente várias questões práticas e técnicas em relação à execução de estudos de mapeamento. Atualmente, a genotipagem de uma amostra com o chip da
Illumina para bovinos (Bovine SNP50®) tem um custo da ordem de US $\$ 200$ por amostra, e está disponível na forma de serviço terceirizado por empresas prestadoras de serviço, o que elimina a necessidade de investimentos em equipamentos especializados e também de mão-de-obra para a geração dos dados moleculares. Como a amostra é manuseada apenas uma vez, erros laboratoriais são minimizados. A análise de dados é altamente automatizada e como os ensaios são conduzidos com altos níveis de redundância (o mesmo SNP é genotipado mais de 10 vezes no mesmo ensaio), erros de genotipagem são reduzidos para índices menores que $0.01 \%$. Todas essas questões tornaram possível realizar a fase de geração de dados moleculares de um estudo de mapeamento em dias, ao invés de meses ou até anos (quando os estudos são feitos com microssatélites).

\section{Seleção genômica}

Os chips de genotipagem de alta densidade tornaram possível a geração de novas aplicações que prometem trazer grandes avanços para os programas de avaliação e melhoramento animal. A alta cobertura do genoma com marcadores ( 1 marcador a cada 50.000 pares de bases) torna possível particionar $100 \%$ da variabilidade genética aditiva de uma característica por todo genoma, permitindo estimarse o valor de substituição de alelo em cada um dos loci envolvidos com a característica. Esse procedimento permite então estimar-se o valor genético de um indivíduo com base nos genótipos de todos os marcadores associados com a característica, ou seja, o valor genômico, sem a coleta da medida fenotípica do indivíduo (Meuwissen et al., 2001). 
O primeiro sumário de touros com valores genômicos foi publicado em janeiro de 2009 pelo USDA para a raça holandesa. Os métodos estatísticos necessários para estimar e aplicar o valor genômico nos programas de avaliação e melhoramento genético, considerando diferentes abordagens e estruturas de populações e dados, estão em franco desenvolvimento e grandes avanços ainda são esperados (Hayes et al., 2009).

\section{Perspectivas para o futuro}

Os chips de genotipagem de alta densidade disponíveis para espécies de interesse zootécnico estão sendo extensamente utilizados por grupos do mundo para desenvolvimento de ferramentas de seleção genômica. No caso dos bovinos, embora os chips atuais sejam adequados para estudos com a maioria das raças taurinas, os estudos em andamento revelaram que em certas raças, principalmente do grupo zebuíno, os marcadores contidos nos chips apresentam informatividade reduzida. Com isso, um número significativo de marcadores não pode ser utilizado nas análises por estar fixado na raça ou por apresentar MAF (Minor Allele Frequency) próxima a zero. Negociações para desenvolvimento de novos chips, com mais marcadores, derivados de um número maior de raças, estão em andamento.

Uma nova onda de tecnologias de seqüenciamento de ácidos nucléicos está prestes a ser lançada no mercado e promete gerar uma nova revolução no campo das ciências genômicas (Eid et al., 2009). A Pacific Biosciences ${ }^{\mathrm{TM}}$ detém uma tecnologia que pode seqüenciar um genoma mamífero em algumas horas, a um custo total entre US\$500 e \$1000. Quando disponível, metodologias como essa mudarão completamente a maneira como se prospecta marcadores SNP. Além disso, é possível imaginar que os chips de genotipagem de alta densidade poderão se tornar obsoletos, já que será possível determinar o genoma de cada indivíduo em um programa de avaliação genética, caracterizando todo e qualquer polimorfismo existente. A única certeza que se tem do futuro é que os próximos anos trarão grandes e estimulantes avanços para o melhoramento animal.

\section{Literatura Citada}

ABATEPAUlO, A.R.; CAETANO, A.R.; MENDES JR., C.T. et al. Detection of SNPs in bovine immune-response genes that may mediate resistance to the cattle tick Rhipicephalus (Boophilus) microplus. Animal Genetics, v.39, n.3, p.328-329, 2008.

ALEXANDER, L.J.; ROHRER, G.A.; BEATTIE, C.W. Cloning and characterization of 414 polymorphic porcine microsatellites. Animal Genetics, v.27, n.3, p.137-148, 1996.

BARENDSE, W.; ARMITAGE, S.M.; KOSSAREK, L.M. et al. A genetic linkage map of the bovine genome. Nature Genetics, v.6, n.3, p.227-35, 1994.
BECKMANN, J.S.; KASHI, Y.; HALLERMAN, E.M. et al. Restriction fragment length polymorphism among Israeli Holstein-Friesian dairy bulls. Animal Genetics, v.17, n.1, p.2538, 1986.

BENNETT, S. Solexa Ltda. Pharmacogenomics, v.5, n.4, p.4338,2004

BOVINE GENOME SEQUENCING AND ANALYSIS CONSORTIUM. The genome sequence of taurine cattle: a window to ruminant biology and evolution. Science, v.324, n.5926, p.522-528, 2009 .

BOVINE HAPMAP CONSORTIUM A Genome-wide survey of SNP variation uncovers the genetic structure of cattle breeds. Science, v.324, n.5926, p.528-532, 2009.

CALVO JH, MARTÍNEZ-ROYO A, SILVERI L, et al. Isolation, mapping and identification of SNPs for four genes (ACP6, CGN, ANXA9, SLC27A3) from a bovine QTL region on BTA3. Cytogenetics and Genome Research, v.114, n.1, p.39-43, 2006.

CHARDON, P.; VAIMAN, M.; KIRSZENBAUM, M.; et al. Restriction fragment length polymorphism of the major histocompatibility complex of the pig. Immunogenetics, v.21, n.2, p.161-71, 1985.

CHESSA, S.; CHIATTI, F.; CERIOTTI, G. et al. Development of a single nucleotide polymorphism genotyping microarray platform for the identification of bovine milk protein genetic polymorphisms. Journal of Dairy Science, v.90, n.1, p.45164, 2007.

COPPIETERS, W.; Van de WEGHE, A.; PEELMAN, L. et al. Characterization of porcine polymorphic microsatellite loci. Animal Genetics, v.24, n.3, p.163-70, 1993.

EID, J.; FEHR, A.; GRAY, J. et al. Real-time DNA sequencing from single polymerase molecules. Science, v.323, n.5910, p.133$138,2009$.

EWING, B.; HILLIER, L.; WENDL, M.C. et al. Base-calling of automated sequencer traces using phred. I. Accuracy assessment Genome Research, v. 8, n.3, p.175-85, 1998

FAHRENKRUG, S.C., FREKING, B.A.; SMITH, T.P. et al. Single nucleotide polymorphism (SNP) discovery in porcine expressed genes. Animal Genetics, v.33, n.3, p.186-95, 2002.

FREDHOLM, M.; WINTERØ, A.K.; CHRISTENSEN, K.; et al. Characterization of 24 porcine $(\mathrm{dA}-\mathrm{dC}) \mathrm{n}-(\mathrm{dT}-\mathrm{dG}) \mathrm{n}$ microsatellites: genotyping of unrelated animals from four breeds and linkage studies. Mammalian Genome, v.4, n.4, p.187-92, 1993.

FRIES, R.; EGGEN, A.; STRANZINGER, G. The bovine genome contains polymorphic microsatellites. Genomics, v.8, n.2, p.403-6, 1990.

GEORGES, M.; LEQUARRÉ, A.S.; HANSET, R.; VASSART, G. Genetic variation of the bovine thyroglobulin gene studied at the DNA level. Animal Genetics, v.18, n.1, p.41-50, 1987.

GUÉRIN, G.; BAILEY, E.; BERNOCO, D. et al. The second generation of the International Equine Gene Mapping Workshop half-sibling linkage map. Animal Genetcis, v.34, n.3, p.161$168,2003$.

GORDON, D.; ABAJIAN, C.; GREEN, P. Consed: a graphical tool for sequence finishing. Genome Research, v.8, n.3, p.195202, 1998.

HACIA, J.G.; FAN, J.B.; RYDER, O. et al. Determination of ancestral alleles for human single-nucleotide polymorphisms using highdensity oligonucleotide arrays. Nature Genetics, v.22, n.2, p.164-7, 1999.

HAYES, B.J.; BOWMAN, P.J.; CHAMBERLAIN, A.J. et al. Invited review: genomic selection in dairy cattle: progress and challenges. Journal of Dairy Science, v.92, n.2, p.433-43, 2009.

HEATON, M.P.; HARHAY, G.P.; BENNETT, G.L. et al. Selection and use of SNP markers for animal identification and paternity analysis in U.S. beef cattle. Mammalian Genome, v.13, n.5, p.272-81, 2002. 
HEATON, M.P.; KEEN, J.E.; CLAWSON, M.L. et al. Use of bovine single nucleotide polymorphism markers to verify sample tracking in beef processing. Journal of the American Veterinary Medicine Association, v.226, n.8, p.1311-1314, 2005.

HOLLOWAY, J.W.; BEGHÉ, B.; TURNER, S. et al. Comparison of three methods for single nucleotide polymorphism typing for DNA bank studies: sequence-specific oligonucleotide probe hybridisation, TaqMan liquid phase hybridisation, and microplate array diagonal gel electrophoresis (MADGE). Human Mutations, v.14, n.4, p.340-7, 1999.

HOPMAN, T.J.; HAN, E.B.; STORY, et al. Equine dinucleotide repeat loci COR001-COR020. Animal Genetics, v.30, n.3, p.225-226, 1999.

JOHANSSON, M.; ELLEGREN, H.; ANDERSSON, L. Cloning and characterization of highly polymorphic porcine microsatellites. Journal of Heredity, v.83, n.3, p.196-198, 1992.

KAMIÑSKI, S.; AHMAN, A.; RUSC, A. et al. MilkProtChip-a microarray of SNPs in candidate genes associated with milk protein biosynthesis - development and validation. Journal of Applied Genetics, v.46, n.1, p.45-58, 2005.

KIRKPATRICK, B.W.; BRADSHAW, M.; BARENDSE, W.; DENTINE, M.R. Development of bovine microsatellite markers from a microsatellite-enriched library. Mammalian Genome, v.6, n.8, p.526-8, 1995.

LAI, E.; RILEY, J.; PURVIS, I. et al. A 4-Mb high-density single nucleotide polymorphism-based map around human APOE. Genomics, v.54, n.1, p.31-38, 1998.

LI, R.; LI, Y.; FANG, X. et al. SNP detection for massively parallel whole-genome resequencing. Genome Research [Epub ahead of print], May 6, 2009.

MAEDA, M.; MURAYAMA, N.; ISHII, H. et al. A simple and rapid method for HLA-DQA1 genotyping by digestion of PCRamplified DNA with allele specific restriction endonucleases. Tissue Antigens, v.34, n.5, p.290-298, 1989.

MARGULIES, M.; EGHOLM, M.; ALTMAN, W.E. et al. Genome sequencing in microfabricated high-density picolitre reactors. Nature, v.437, n.7057, p.376-380, 2005.

MARKLUND, S.; ELLEGREN, H.; ERIKSSON, S. et al. Parentage testing and linkage analysis in the horse using a set of highly polymorphic microsatellites. Animal Genetics, v.25, n.1, p.19-23, 1994.

MATUKUMALLI, L.K.; LAWLEY, C.T.; SCHNABEL, R.D. et al. Development and characterization of a high density SNP genotyping assay for cattle.PLoS ONE, v.4, n.4, e5350, 2009.

MEUWISSEN, T.H.E.; HAYES, B.J.; GODDARD, M.E. Prediction of total genetic value using genome wide dense marker maps. Genetics, v.157, p.1819-1829, 2001.

MILLER, J.R.; DIXON, S.C.; MILLER, N.G. et al. A chromosome 1-specific DNA library from the domestic pig (Sus scrofa domestica). Cytogenetics and Cell Genetics, v.61, n.2, p.128-31, 1994.

MOORE, S.S.; BYRNE, K.; BERGER, K.T. et al. Characterization of 65 bovine microsatellites. Mammalian Genome, v.5, n.2, p.84-90, 1994.

MURPHIE, A.M.; HOPMAN, T.J.; SCHUG, M.D. et al. Equine dinucleotide repeat loci COR021-COR040.Animal Genetics, v.30, n.3, p.235-237, 1999.

NOVAES, E.; DROST, D.R.; FARMERIE, W.G. et al. Highthroughput gene and SNP discovery in Eucalyptus grandis, an uncharacterized genome. BMC Genomics, v.30, n.9, p312, 2008.

ORITA, M.; IWAHANA, H.; KANAZAWA, H. et al. Detection of polymorphisms of human DNA by gel electrophoresis as singlestrand conformation polymorphisms. Proceedings of the National Academy of Sciences USA, v.86, n.8, p.2766-70, 1989.

REED, K.M.; MENDOZA, K.M.; BEATTIE, C.W. Development of 90 new bovine microsatellite loci.Animal Biotechnology, v.12, n.1, p.69-76, 2001.

ROHRER, G.A.; ALEXANDER, L.J.; KEELE, J.W. et al. A microsatellite linkage map of the porcine genome. Genetics, v.136, n.1, p.231-45, 1994.

RUTH, L.S.; HOPMAN, T.J.; SCHUG, M.D. et al. Equine dinucleotide repeat loci COR041-COR060. Animal Genetics, v.30, n.4, p.320-321, 1999.

SAIKI, R.K.; BUGAWAN, T.L.; HORN, G.T. et al. Analysis of enzymatically amplified beta-globin and HLA-DQ alpha DNA with allele-specific oligonucleotide probes. Nature, v.324, n.6093, p.163-166, 1986.

STONE, R.T.; KAPPES, S.M.; KEELE, J.W.; BEATTIE, C.W. Characterization of 109 bovine microsatellites. Animal Genetics, v.28, n.1, p.62-66, 1997.

STONE, R.T.; PULIDO, J.C.; DUYK, G.M. et al. A small-insert bovine genomic library highly enriched for microsatellite repeat sequences. Mammalian Genome, v.6, n.10, p.714-24, 1995.

TANG, K.; FU, D.J.; JULIEN, D. et al. Chip-based genotyping by mass spectrometry. Proceedings of the National Academy of Sciences USA, v.96, n.18, p.10016-20, 1999.

VAIMAN, D.; MERCIER, D.; MOAZAMI-GOUDARZI, K. et al. A set of 99 cattle microsatellites: characterization, synteny mapping, and polymorphism. Mammalian Genome, v.5, n.5, p.288-97, 1994.

Van TASSELL, C.P.; SMITH, T.P.; MATUKUMALLI, L.K. et al. SNP discovery and allele frequency estimation by deep sequencing of reduced representation libraries. Nature Methods, v.5, n.3, p.247-52, 2008.

VALOUEV, A.; ICHIKAWA, J.; TONTHAT, T. et al. A highresolution, nucleosome position map of $\mathrm{C}$. elegans reveals a lack of universal sequence-dictated positioning. Genome Research, v.18, n.7, p.1051-1063, 2008. 